\title{
"Ethical and Regulatory Issues in Genetic Research Collaboration between Global Pharmaceutical Industry and Low- and Middle-income Countries"
}

Iman Sharawy ( $\nabla$ emanelsharawy@med.asu.edu.eg )

Ain Shams University

\section{Research Article}

Keywords: Genetic research collaboration, Global Pharmaceutical Industry, Low- and Middle-income Countries, COVID-19, Research Ethics

Posted Date: February 17th, 2022

DOI: https://doi.org/10.21203/rs.3.rs-1319747/v1

License: (c) (1) This work is licensed under a Creative Commons Attribution 4.0 International License.

Read Full License 


\section{Abstract}

\section{Background:}

The global pharmaceutical industry (big pharma) is responsible for production, and distribution of drugs. Big pharma revenues have been growing markedly totaling about 1.27 trillion U.S. dollars in 2020. Lowand middle-income countries spend only $1.46 \%$ of their Gross Domestic Products (GDP) on research and development necessitating collaboration with big pharma. Genetic research require access to sophisticated laboratories, large-scale genotyping facilities, bioinformatics and statistical expertise which cannot be afforded by low or middle-income countries. Consequently, most of the genetic research is conducted in high-income countries and big pharma.

\section{Main body:}

This paper has three aims: the first aim is to identify ethical and regulatory issues related to genetic research collaboration of big Pharma with low and middle-income countries. The second aim is to explain the impact of non-collaboration of big pharma with low and middle-income countries. The third aim is to propose a future ethical and regulatory framework for genetic research of big pharma with lowand middle-income countries. To accomplish these aims the big pharma revenue and spending was outlined, the necessity of genetic collaboration was highlighted and the resultant ethical and regulatory gaps were elaborated. The COVID-19 mRNA vaccine was mentioned as an illustration for noncollaboration. Then a future ethical and regulatory framework for genetic research of big pharma with low- and middle-income countries at the international, national and research ethics committee levels was proposed.

\section{Conclusion:}

This paper identified several ethical and regulatory issues related to genetic research collaboration and non-collaboration of big Pharma with low and middle-income countries followed by proposing a future ethical and regulatory framework for collaboration at the international, national and research ethics committee levels.

\section{Background}

\section{Big Pharma revenue and spending}

Big pharma conducts research and development (R\&D) and is responsible for production, and distribution of drugs. Big pharma revenues have been growing markedly totaling about 1.27 trillion U.S. dollars in 2020. In 2020, the North American region accounted for almost half of this revenue while Roche (the Swiss pharma giant) was the top in pure pharma revenue worldwide and in R\&D spending. In 2018, the top therapeutic classes and drugs generating revenues wereoncologic drugs, analgesics, and drugs for diabetes. ${ }^{1}$ 


\section{Pharmaceutical R\&D spending}

Research and development in big pharma involves the identification and development of compounds used to make new drugs. Among all industries, the pharmaceutical industry has the largest percentage of spending attributable to R\&D. Big Pharma spends a lot of money on marketing too, as it is estimated that \$19 are spent on promotions and advertising for every \$1 spent on "basic research,." ${ }^{2}$ Total pharma advertising spending topped $\$ 6.58$ billion in $2020{ }^{3}$

\section{New pharmaceutical products}

Globally, the U.S. big pharma created the largest number of new drugs and compounds between 2015 and 2019 , followed by Europe. Unfortunately, not all new drugs succeed on development, over half of all drugs fail between phase I and phase II alone. ${ }^{1}$

\section{Low-income, middle-income, and high-income countries}

According to the World Bank, countries are classified into low-income, middle-income, or high-income economies according to Gross National Income (GNI) per capita. ${ }^{4}$

\section{The need for genetic research collaboration}

As low- and middle-income countries spend only $1.46 \%$ of their GDP on R\&D, ${ }^{5}$ and as genetic research require access to sophisticated laboratories, large-scale genotyping facilities, statistical expertise, and bioinformatics, so genetic research collaboration is inevitably needed between big pharma and low-and middle-income countries.

\section{Impact of non-collaboration of big pharma with low and middle-income countries}

Although World Trade Organization mission is to promote free trade and technology transfer, yet during the COVID-19 pandemic it seemed to protect patent monopolies, bans, or severely restricts non-disclosure agreements resulting in bottling up technology. The issue of bottling up technology was raised during COVID-19 pandemic when the global vaccine supply decreased, vaccine prices' soared and millions of lives were lost. The provisions of the Agreement on Trade-Related Aspects of Intellectual Property Rights (TRIPS Agreement) require countries throughout the world to have US-type patent laws. Although more than 100 low- and middle-income countries support a TRIPS Agreement waiver (to temporarily waive intellectual property rights protections for technologies needed to prevent, contain, or treat COVID19 including vaccines and vaccine-related technologies), yet nothing has happened so far at the international level.

Even if middle-income countries have the technical expertise to produce the COVID mRNA vaccines, they cannot start shifting production to pandemic-related items because they need to have the authorization of manufacturers who have patent rights. Not only does low- and middle-income countries need 
technology transfer, but they need disclosure of industrial secrets too. Companies cannot be forced to disclose secret information, their top engineers cannot share their expertise or their know-how with other countries (due to non-disclosure agreements), if engineers share information, they will face lawsuits. In short, the laws on non-disclosure agreements are used by big pharma to block technology transfer. ${ }^{6}$ This raise ethical concerns about equity, fairness, and the fundamental principle of ethics "First do no harm".

\section{Collaboration between big pharma and big technology (big tech) companies:}

Pharma giant Pfizer signed an agreement with technology pioneer BioNTech and produced a COVID-19 mRNA vaccine which was approved for worldwide use. The pair have now teamed up with other big pharma companies (Novartis, Sanofi and Merck) to support manufacturing their vaccine. Other collaborations or acquisitions between big pharma and big tech companies are seen in the pharma landscape, e.g., Amazon's acquisition of PillPack, Amazon Pharmacy, Google and its own healthcare company (Verily), and finally Boehringer Ingelheim and Google in pharma R\&D.

The three companies behind two of the most successful COVID-19 vaccines -Pfizer, BioNTech and Moderna - are making combined profits of $\$ 65,000$ every minute. Delivering less than $1 \%$ of Pfizer and BioNTech total vaccine supplies and only $0.2 \%$ of Moderna to low-income countries, while $98 \%$ of lowincome countries people have not been fully vaccinated raises not only ethical concerns but regulatory concerns too. ${ }^{7}$ Based on Pfizer, BioNTech and Moderna financial statements, it is estimated that these companies make pre-tax profits of $\$ 34$ billion (over a thousand dollars a second or $\$ 93.5$ million a day). ${ }^{8}$

This example of non-collaboration raises many questions. Are people living in low- and middle-income countries voiceless regarding their own health? Are international agreements, conventions, or resolutions only slogans? Is inequality becoming the new normal? Are big pharma policies and big tech companies becoming the new soft power? Is equitable access to COVID-19 vaccines not considered one of the human rights in low- and middle-income countries? How can the sustainable developmental goals (SDG) signed by governments be achieved in low-and middle-income countries? What message is big pharma and big tech companies sending to low- and middle-income countries? Will every country try to solve the COVID-19 pandemic and its impact alone? Will big pharma policies lead to political unrest? Will this result in a new phase of international relations with new economic and regulatory frameworks relying on multinational companies (big pharma and big tech companies' policies that are independent of countries' governments?

Are the United Nations General Assembly (UNGA) resolutions A / RES/74/270 "Global solidarity to fight the coronavirus disease 2019 (COVID-19)" ${ }^{9}$ and A/RES/74/274 "International cooperation to ensure global access to medicines, vaccines and medical equipment to face COVID-19", ${ }^{10}$ the World Health Assembly resolutions WHA73.1 "COVID-19 response"11 and WHA73.8 "Strengthening preparedness for health emergencies: implementation of the International Health Regulations (IHR) (2005)"12, UNGA resolutions A/74/L.92 "Comprehensive and coordinated response to the coronavirus disease (COVID-19) pandemic", ${ }^{13}$ and A/74/L.57, "United response against global health threats: combating COVID-19", ${ }^{14}$, 
Human Rights Council resolution A / HRC/46/L.25/Rev.1, "Ensuring equitable, affordable, timely and universal access for all countries to vaccines in response to the coronavirus disease (COVID-19) pandemic," 15 not for implementation if related to genetic science, or low-and middle-income countries, or big pharma and big tech companies? Being one of the ordinary people (not a politician or a representative for these international organizations, it is difficult to understand why resolutions concerning public health are not implemented. If this is becoming the new normal amidst a pandemic, will the future of low- and middle-income countries' public health be in the hands of big pharma and big tech companies?

\section{Ethical issues and regulatory gaps in genetic collaboration}

Although global genetic research collaboration has the potential to address global health challenges, yet there are several ethical issues and regulatory gaps when big pharma collaborates with low- and middleincome countries which can be grouped into:

\section{1) Genetic research collaboration governance:}

Such collaboration can lead to potential exploitation of low- and middle-income countries or "ethics dumping" which refers to the tendency of big pharma to take advantage of a lack of ethics oversight and governance structures in low- and middle-income countries in order to conduct research that is either illegal or ethically problematic in their own countries, ${ }^{16}$ (e.g., conducting research before publishing the results of phase I and phase II studies or enrolling participants in low- and middle-income countries before enrolling patients in the country of origin of the trial). Illiteracy in low- and middle-income countries and poverty in low-income countries may aggravate this exploitation. Exploitation may be unintentional due to lack of awareness of relevant contextual information such as culture. The undeveloped regulatory frameworks between different countries create ethically gray zone research which poses extra burden on national or institutional research ethics committees.

Genetic research is conducted in the context of resource inequalities between big pharma and researchers in low- and middle-income countries, the concentration of resources and samples in big pharma raise questions about fairness and benefit sharing. Sample export in the absence of agreed-upon policies for export, sample handling and destruction, ${ }^{17,18}$ sample commercialization and monetization, ${ }^{19}$ samples' ownership, data ownership and data commercialization raise many ethical concerns. Transfer of samples or data to unknown third parties for processing, quality control and genotyping results raises concerns for unpredictable risks and dual use of samples and data e.g., if a third party is a company that has a medical and military research divisions. Other ethical concerns include cultural value for tissues and samples, not returning genetic results for medically actionable results, uncertain future of the samples and sample depletion.

Although big pharma signs an insurance for research participants in case of severe adverse events or mortality, there is no insurance for tissue sample loss, destruction, or genetic data manipulation. Consent is written in a long, ambiguous or legalese vocabulary raising suspicion of valid consenting. 
The regulatory framework of most low- and middle-income countries do not include a stance towards germ-line gene therapy, in utero trials and first-in-human trials. Germ-line gene therapy involves germ-line cells alteration (sperm cells or ova) of an individual, so that offspring will also be affected. Such trials raise serious ethical concerns worldwide due to unpredicted effects on future generations.

\section{2) Ethical issues related to research participants:}

Ethical issues as privacy, confidentiality and sample ownership may rise in biological sample collection, using archived or fresh tissue samples from healthy participants or diseased participants e.g., in neoadjuvant settings in treating cancer, tissue samples may be collected twice; before and after treatment to serve as in vivo test for drug efficacy. Conducting genetic studies during such research leads to in depth understanding of genetic alterations during treatment but may lead to tissue sample depletion, not returning the research results to research participants (due to different regulatory frameworks) may lead to duplication of studies, opportunity loss for treatment with a further different drugs in case of failure or resistance to the former drug.

Although data sharing is ethically justified by the principles of justice and beneficence, ${ }^{20}$ transparency, reproducibility and accountability, ${ }^{21}$ yet ethical issues may be raised due to privacy, equity, consenting, governance, ${ }^{22}$ anonymity; ${ }^{23}$ collecting and storing vast amounts of data; data release implications for non-medically actionable results, stigmatization, ${ }^{24}$ trust, autonomy, ${ }^{25}$ data security and data ownership.

Genomic studies may involve unique ethical challenges. Prenatal testing when conducted through a direct-to-consumer pathway and then sold to big pharma (as a third party), raising issues of reliability of results, justification for induced abortion or other implications that occur due to results release.

Preimplantation genetic testing of embryos produced through in vitro fertilization (IVF) poses risks of enhancement, eugenics, or sex selection while neuroimaging genetics studies may involve stigma issues and exploitation.

Gene therapy involves somatic cell gene therapy or germ-line gene therapy. Somatic cell gene therapy involves genes alteration of the affected individual's somatic cells (non-reproductive cells), the modified genome is not transmitted to future offspring. Various ethical concerns and regulatory gaps are raised in case of in low- and middle- income gene therapy trials as ethics dumping and vulnerability e.g., experimenting in children through an unapproved route of administration of drugs before enrolling patients of the trial country of origin, gene modifications for enhancement purposes not for therapy e.g., correcting eyesight to greater than $20 / 20$, improving memory.

\section{3) Ethical issues related to researchers:}

Sharing genomics research projects' data with third party researchers for secondary analysis raises the issue of equality and fairness because not all researchers in low- and middle-income countries have equal access to the data or comparable facilities and abilities to analyze it. 


\section{Proposed ethical and regulatory framework}

\section{At the international level:}

In agreement with The People's Vaccine Alliance (including ActionAid, the African Alliance, Global Justice Now, Oxfam and UNAIDS) who proposed: temporary suspension of intellectual property rights for COVID vaccines, tests, treatments (via agreement to the temporary TRIPS Agreement waiving), share the knowhow and technology, improve access of COVID-19 vaccines equitably to all countries, ${ }^{26}$ ensure purchase of COVID-19 vaccines at true cost prices, provide them free of charge to people, prevent monopolies on vaccine and treatment production and implement fair allocation of COVID-19 vaccines to all countries. ${ }^{27}$

Initiate a debate among all stakeholders including governments, big pharma, big tech companies and civil society about first: the contribution that can be offered by big pharma and big tech companies to people to ensure sustainable and long-term investment in global public health. Second: how can healthy competition be assured without violating intellectual property rights to promote global public health. Third: How can the health system regulatory frameworks be modified to avoid regulatory gaps when dealing with global public health.

\section{At the national level:}

The Global Code of Conduct for Research in Resource-Poor Settings is founded on fairness, respect, care, and honesty to ensure ethical research conduction in resource poor settings. It forms the basis for ethical conduct between stakeholders in collaborative research. ${ }^{28}$

To ensure sustainability, mutually beneficial collaborations and as a corporate social responsibility contribution, big pharma can share in capacity building across participating research sites in low-and middle-income countries, invest in infrastructure for genotyping, whole genome analysis, genome wide association studies (GWAS), and whole-exome sequencing studies (WES) through promoting technology transfer and supporting supply chain processes. Big pharma can establish central data repositories for genomic data where data can be securely stored, easily accessed and available for data extraction and/or analysis. They can invest in effective high-speed connectivity to the internet, high speed computers, well-trained IT staff and bioinformatics scientists. If big pharma invests in the infrastructure supporting genomic studies, this will safeguard against both intentional and unintentional exploitation.

Governments in low- and middle-income countries should ensure regulatory oversight of genetic collaboration, ensure that appropriate mechanisms are in place, develop regulations for genomic editing, gene therapy, reprogramming of exported tissue or sample (before exportation) and first-in-human trials. The governance system should be dynamic to accommodate the evolving science and technology.

As data sharing has several implications, it is appropriate to have more than one-model or standardized approach to governance to adapt for diverse research contexts. Ethical data sharing has been proposed: engage all stakeholders, minimize harm to populations and research participants, promote fairness and 
reciprocity, ensure relevance of research to communities' health needs, and develop trust among all stakeholders. ${ }^{29}$

Research site members should retain ownership of their data. Ensure co-authorship on all derived published papers. ensure the appropriate recognition of local investigators' contributions and capacity development.

\section{At the research ethics committees (RECs) or institutional review boards (IRBs) level:}

First: a mandatory submission of a signed Material Transfer Agreement (MTA) to RECs or IRBs describing in detail the samples to be exported or transferred, the exact work to be done on the samples; conditions of samples' storage, details on samples access and security; personnel to work with, the principal investigator and co-investigators; the duration of the collaboration, and procedures conducted for sample return or destruction at the end of the study. MTA is instrumental in addressing sample and data ownership, long-term storage, and sample re-use concerns.

Second: a mandatory submission of a Limited Data Use Agreements (DUAs) or Data Transfer Agreement (DTA) to RECs or IRBs regulating data access, data sharing or derived data and data ownership. Limited access to datasets can be mediated through an independent data-access committee. Researchers can be granted access to genotyping data and to a limited amount of phenotypic data only after signing a legally binding data-access agreement as unrestricted public access is inappropriate.

Finally: third parties should be known and if a new third party would be involved during the study, notification of the RECs or IRBs should be done.

\section{Conclusion}

Genetic research needs collaboration between low- and middle-income countries and big pharma. This paper identified several ethical and regulatory issues related to genetic research collaboration and noncollaboration of big Pharma with low and middle-income countries followed by proposing a future ethical and regulatory framework.

\section{Abbreviations}

Gross Domestic Products GDP

Research and development R\&D

Gross National Income GNI

Trade-Related Aspects of Intellectual Property Rights TRIPS

Sustainable developmental goals SDG 
International Health Regulations IHR

In vitro fertilization IVF

Genome wide association studies GWAS

Whole-exome sequencing studies WES

Research ethics committees RECs

Institutional review boards IRBs

Material Transfer Agreement MTA

Data Use Agreements DUAs

Data Transfer Agreement DTA

\section{Declarations}

\section{Ethics approval and consent to participate}

Not applicable.

\section{Consent for publication}

Not applicable

\section{Availability of data and materials}

Datasets were not generated in this article. All data that support the findings in this study are included in the published article.

\section{Competing interests}

The author declares no financial or non-financial competing interests

\section{Funding}

The author declares that this is self-funded.

\section{Authors' contributions}

The author designed the work, conducted the ethical and regulatory analysis, drafted and revised the article, and approved the submitted version.

\section{Acknowledgements}


The author wishes to acknowledge the anonymous peer reviewers for their valuable comments and the editorial support team for their help during submission of this manuscript.

\section{References}

1. Matej Mikulic, Global pharmaceutical industry - statistics \& facts, 2021, Health, Pharma \& Medtech, Pharmaceutical Products \& Market, https://www.statista.com/topics/1764/global-pharmaceuticalindustry/\#dossierKeyfigures (accessed on 17 December 2021)

2. Donald W Light,Joel R Lexchin, Pharmaceutical research and development: what do we get for all that money? BMJ2012; 345 doi: https://doi.org/10.1136/bmj.e4348 (Published 07 August 2012)

3. Beth Snyder Bulik, The top 10 ad spenders in Big Pharma for 2020, Special report, 2021 https://www.fiercepharma.com/special-report/top-10-ad-spenders-big-pharma-for-2020 (accessed on 17 December 2021)

4. World Bank Country and Lending Groups, the World Bank, Data, According to UNESCO Institute for Statistics (uis.unesco.org). Data as of September 2021(Accessed on 17 December 2021 https://datahelpdesk.worldbank.org/knowledgebase/articles/906519-world-bank-country-andlending-groups

5. Research and development expenditure (\% of GDP), UNESCO Institute for Statistics (uis.unesco.org). Data as of September 2021. https://data.worldbank.org/indicator/GB.XPD.RSDV.GD.ZS (Accessed 17 December 2021)

6. Dean Baker. We Need to Shrink Big Pharma Until It's Small Enough to Drown in a Bathtub, 2021. JACOBIN, 09.20.2021. https://www.jacobinmag.com/2021/09/pharmaceutical-industry-patentstrips-covid-19-deaths-vaccine

7. Press releases, published 16th November 2021, https://www.oxfam.org/en/press-releases/pfizerbiontech-and-moderna-making-1000-profit-every-second-while-worlds-poorest (Accessed 20 December 2021)

8. Rohit Malpani and Alex Maitland. Dose of Reality: How rich countries and pharmaceutical corporations are breaking their vaccine promises. A Dose of Reality-Briefing Note 21 OCTOBER 2021.pdf https://app.box.com/s/hk2ezb71vf0sla719jx34v0ehs0l22os (downloaded 20 December 2021)

9. Available at https://undocs.org/A/RES/74/270.

10. Available at https://undocs.org/en/A/RES/74/274.

11. Available at https://apps.who.int/gb/ebwha/pdf_files/WHA73/A73_R1-en.pdf.

12. Available at https://apps.who.int/gb/ebwha/pdf_files/WHA73/A73_R8-en.pdf.

13. Available at https://undocs.org/A/74/L.92.

14. Available at https://undocs.org/A/74/L.57.

15. Available at https://undocs.org/A/HRC/46/L.25/Rev.1. 
16. Schroeder, D, Cook, J, Hirsch, F, Fenet, S, Muthuswamy, V. Ethics dumping: Intro- duction In. In: Schroeder, D, Cook, J, Hirsch, F, Fenet, S, Muthuswamy, V (Eds.), Ethics Dumping Case Studies from North-South Research Collaborations editors. 2018, Springer International Publishing, Cham.

17. Muula AS, Mfutso-Bengo JM: Responsibilities and obligations of using human research specimens transported across national boundaries. J Med Ethics 2007, 33(1):35-38.

18. Langat SK: Reuse Of Samples: Ethical Issues Encountered By Two Institutional Ethics Review Committees In Kenya. Bioethics 2005, 19(5-6):537-549.

19. Dickenson D: Human Tissue and Global Ethics. Genomics, Society and Policy 2005, 1(1):41-53.

20. Bezuidenhout, L, Chakauya, E. Hidden concerns of sharing research data by low/middle-income country scientists. Glob. Bioeth. 2018, 29 (1), 39-54. doi: 10.1080/11287462.2018.1441780.

21. Milham, MP, Craddock, RC, Son, JJ, Fleischmann, M, Clucas, J, Xu, H, et al. As- sessment of the impact of shared brain imaging data on the scientific literature. Nat. Commun. 2018, 9 (1), 2818. doi: 10.1038/s41467-018-04976-1.

22. Lunshof JE, Chadwick R, Vorhaus DB, Church GM: From genetic privacy to open consent. Nat Rev Genet 2008, 9(5):406-411.

23. Vayena, E, Blasimme, A. Health research with big data: time for systemic oversight. J. Law, Med. Ethics 2018, 46 (1), 119-129. doi: 10.1177/1073110518766026.

24. Caulfield T, McGuire AL, Cho MK, Buchanan JA, Burgess MM, Danilczyk U, Diaz CM, Fryer-Edwars K, Green SK, Hodosh MA, et al: Research Ethics Recommendations for Whole-Genome Research: Consensus Statement. Plos Biology 2008, 6(3):e73.

25. Ellison GTH, Jones IR: Social identities and the 'new genetics': scientific and social consequences. Critical Public Health 2002, 12(3):265-282.

26. UNAIDS, A Dose of Reality: How rich countries and pharmaceutical corporations are breaking their vaccine promises, Featured story. October 2021 https://www.unaids.org/en/resources/presscentre/featurestories/2021/october/20211021_dose-ofreality (Accessed 21 December 2021)

27. THE PEOPLE'S VACCINE. https://peoplesvaccine.org (Accessed 21 December 2021)

28. Global Code of Conduct for Research in Resource-Poor Settings. 2018. https://www.globalcodeofconduct.org/wp-content/uploads/2018/05/Global-Code-of-ConductBrochure.pdf (Downloaded 18 December 2021)

29. Bull, S, Cheah, PY, Denny, S, Jao, I, Marsh, V, Merson, L, et al. Best practices for ethical sharing of individual-level health research data from low- and middle-income settings. J Empir. Res. Hum. Res. Ethics 2015, 10 (3), 302-313. doi: 10.1177/1556264615594606. 